\title{
Restauración y reciclaje del Centro de Documentación Adolfo López Mateos: Análisis del proceso constructivo y de equipamiento
}

\author{
Merizanda Ramírez Aceves \\ Marcos Mejía López \\ María Esther Morales-Fajardo
}

Artículo

Afiliación: Universidad Autónoma del Estado de México (UAEMéx), Toluca, México.

\section{E-mail: Merizanda Ramírez Aceves \\ merizanda@hotmail.com \\ Marcos Mejía López: \\ marcmejilop@hotmail.com \\ María Esther Morales-Fajardo: \\ moralesf@crim.unam.mx}

Recibido: 20 de abril del 2020

Aceptado: 29 de octubre del 2020

\section{Merizanda Ramírez Aceves}

Doctora en Documentación por la Universidad Carlos III de Madrid, Profesora de Tiempo Completo de la Facultad de Humanidades de la Universidad Autónoma del Estado de México (UAEMéx), Miembro del Sistema Nacional de Investigadores, Nivel 1 , Conacyt.

\section{Marcos Mejía López}

Doctor en Arquitectura por la Universidad Politécnica de Cataluña. Profesor-investigador de tiempo completo de la Facultad de Arquitectura y Diseño de la UAEMéx, conservador del patrimonio histórico arquitectónico de la UAEMéx, Académico por la Real Academia Catalana de Bellas Artes de Sant Jordi de Barcelona, España.

\section{María Esther Morales-Fajardo}

Doctora en Ciencias Sociales con especialidad en Relaciones Internacionales por la Universidad Autónoma Metropolitana-Xochimilco. Investigadora titular del Centro Regional de Investigaciones Multidisciplinarias de la UNAM. Profesora de asignatura de la Facultad de Economía de la UAEMéx. Miembro del Sistema Nacional de Investigadores, Conacyt.

\section{Resumen:}

Los centros de documentación son espacios difusores de la información organizada y especializada para usuarios. Sin embargo, tanto la adecuada planeación como la edificación de estos espacios no cuentan con una normativa específica en México. El objetivo de este artículo es analizar las características que deberían cumplir y el proceso constructivo que dio origen al Centro de Documentación Presidente Adolfo López Mateos de la UAEMéx. El texto revisa la literatura especializada en centros de documentación, también considera dos propuestas de restauración y reciclaje de edificios históricos para detallar el proceso constructivo y de equipamiento de estos recintos documentales. Se concluye que este centro de documentación debería constituir y difundir un fondo documental especializado, no sólo producido por la propia institución, sino también promover la docencia, la investigación y otros servicios documentales. Además, las técnicas de restauración y reciclaje empleadas permitieron el uso eficiente del espacio que actualmente ocupa. De igual manera, se defiende la idea de aplicar estos métodos provenientes de la arquitectura antes de la construcción de espacios nuevos.

Palabras clave: Centro de documentación, fondos documentales, reciclaje arquitectónico, restauración arquitectónica.

\section{Restoration and recycling of the Adolfo López Mateos Documentation Center: Analysis of the construction and equipment process}

\begin{abstract}
:
Documentation Centers are disseminating spaces for organized and specialized information for users. However, the proper planning and, even more, the construction process of these spaces do not have specific regulation in Mexico. The aim of this article is to analyze the suitable characteristics and the construction process of the Documentation Center President Adolfo López Mateos of the UAEMéx. The article reviews the specialized literature on Documentation Centers and considers the restoration and recycling proposals of historical buildings. It also analyses the construction and equipment process. It is concluded that this Documentation Center should constitute and disseminate a specialized documentary archive not only produced by the institution itself. But, promote teaching, research and other documentary services. In addition, the use of restoration and recycling techniques allowed the efficient rescue of the space. Similarly, the idea of applying these methods from architecture before the construction of new spaces is defended.
\end{abstract}

Keywords: Architectonic recycling, architectonic restoration, documentary background, Documentation Center. 


\section{Introducción}

os centros de documentación poseen relevancia como difusores de la información organizada y especializada a un conjunto de usuarios que la demandan. Encina (1994), Ros (1996) y Millán (2003) señalan la importancia de los centros de documentación para difundir la información y enuncian sus principales características para la catalogación, tratamiento y conservación de los materiales que disponen. Al respecto, otros autores como López de Quintana (1995) y Sargent, Parker y Marcella (2000) coinciden en resaltar la importancia de una adecuada planificación de estos lugares para la correcta ejecución de sus funciones.

En México se han instrumentado centros de documentación en la mayoría de las instituciones públicas, privadas y sociales. No obstante, la literatura que analiza el proceso de planeación para la edificación y funcionamiento de estos recintos es escasa, así lo evidencia en su análisis temático Herrera-Miranda, Licea de Arenas, \& Gómez-Hernández (2013), quienes estudiaron una muestra de 106 títulos en un periodo de 50 años de las publicaciones mexicanas científicas en torno a la biblioteconomía, documentación, bibliotecología y ciencias de la información. De los pocos estudios que hay hasta el momento destaca el de Gutiérrez, Zárate \& Mirabal (2010), quienes analizan el proceso constructivo del Centro Información y Documentación de la Universidad Politécnica de San Luis Potosí, a partir de la elaboración de un programa de necesidades de espacios universitarios para la operación de un sistema de información documental que apoyara las necesidades de docencia e investigación.

En México, como seguramente en diversas naciones de América Latina, no existe un acompañamiento formal entre el proceso constructivo y los especialistas en documentación que permitan el diseño, la construcción y el correcto funcionamiento de los inmuebles que resguardan fondos documentales. La Universidad Autónoma del Estado de México (UAEMéx) cuenta con el Centro de Documentación Presidente Adolfo López Mateos desde el año 2018, que alberga documentación personal de este presidente y del antecedente de esta universidad que es el Instituto Científico y Literario Autónomo (ICLA). Sin embargo, este centro funciona casi como un archivo histórico (Universidad Autónoma del Estado de México, 2020), aunque para su proceso constructivo y de funcionamiento estuvo acompañado por especialistas del área.

El objetivo de este documento es analizar las características que debió cumplir y el proceso constructivo que dio origen al Centro de Documentación Presidente Adolfo López Mateos de la UAEMéx. El análisis es importante porque este espacio cumple con el anhelo universitario de resguardar los fondos documentales a su cargo, no obstante, aún le falta concretar las tareas sustanciales que le permitan un adecuado funcionamiento. Este documento ha sido el resultado del encargo institucional para proyectar la construcción de este espacio, para la cual se tuvieron en consideración el resguardo y conservación del edificio histórico de la Rectoría de la UAEMéx (lugar físico en donde se ubica el Centro de Documentación) y el acompañamiento de una especialista en materia de acondicionamiento de los fondos documentales. Es importante aclarar que la coordinación ejecutiva del proyecto fue una decisión que recayó en las autoridades universitarias de su momento.

Metodológicamente, este artículo revisa la literatura especializada en centros de documentación, de restauración y reciclaje de edificios históricos para, posteriormente, profundizar en el proceso constructivo y de equipamiento. Además de esta introducción, un primer apartado discute la definición y características de estos centros. Posteriormente, se describe la funcionalidad del Centro de Documentación Presidente Adolfo López Mateos de la UAEMéx. En seguida se aborda la metodología de restauración y reciclaje de edificios para detallar el proceso constructivo que dio origen a este Centro de Documentación.

Finalmente, se presentan la discusión y las conclusiones del documento. Cabe destacar que el artículo defiende la idea de restaurar y/o reutilizar espacios destinados para este fin antes de optar por la construcción de un inmueble nuevo que demanda un gasto fuerte por parte de la institución que lo requiere. Además de que se aclaran las características que diferencian a un centro de documentación de una biblioteca 0 un archivo, lo que define, al mismo tiempo, los materiales que aquel debe contener. 


\section{Los centros de documentación}

De los centros de documentación que surgieron durante el desarrollo de la ciencia de la documentación, que más tarde se transformaría en Ciencia de la Información, se tiene conocimiento a partir de los estudios de los belgas Paul Otlet y Henry La Fontaine desde finales del siglo XIX y que se prolongan hasta la actualidad con los españoles Ros García, López Yepes, entre otros. Aunque se ha escrito mucho sobre la disciplina, los estudios sobre la institución documentaria no han corrido la misma suerte. En su Tratado de Documentación, la obra más importante que publicaría en los años 30 del siglo XX, tras muchos esfuerzos iniciados desde un siglo anterior, Paul Marie Ghislain Otlet buscó consolidar y difundir un saber científico que fuera más allá de los saberes tradicionales de la bibliotecología, la archivística, la bibliología y la museología. Con ello se configuró una ciencia transdisciplinaria a la que llamó Documentación y cuyo objeto de estudio sería el documento, entendido como: "expresiones escritas de las ideas, instrumentos de su fijación, de su conservación, de su circulación, son los intermediarios obligados de todas las relaciones entre los hombres" (Ayuso, 2004, p. 3).

De esta manera, para Otlet, el documento se convertiría en el artefacto universal para el registro de los conocimientos, posicionándolo por encima del libro (objeto de estudio de la bibliotecología), del documento de archivo (objeto de estudio de la archivística) y de la pieza museística. Dejó claro, además, que la realidad de los hechos, la objetividad/ subjetividad de los individuos y la necesidad de transmitir el conocimiento son: "Ios tres elementos fundamentales que dan origen a las cosas informativas de creación humana, para la vida" (Montilla, 2013, p. 62). Su principal interés se centró en la organización del conocimiento universal. Fue así que junto con Henri La Fontaine fundaron en 1893 el Instituto Internacional de Bibliografía Sociológica, el antecedente de lo que más tarde sería la Oficina Internacional de Bibliografía, de ahora en adelante OIB, y cuyas funciones se enfocaron en la organización de las bibliotecas y en realizar publicaciones, repertorios bibliográficos y compilaciones basadas en los hechos sociales.

De manera simultánea, se creó el Instituto Internacional de Bibliografía, de ahora en adelante IIB, antecedente de lo que hoy se conoce como la Federación Internacional de Documentación, dedicada al estudio de la bibliografía en general y a la elaboración del Repertorio Bibliográfico Universal, de ahora en adelante RBU (Arnau, 1995, p. 158). Este último documento, el RBU, ha sido considerado hasta nuestros días como la obra más importante de estos teóricos, pues consiste en "un inventario clasificado por materias y autores de los libros y publicaciones aparecidas en todos los países, en todas las épocas y sobre todos los temas" (Arnau, 1995, p. 159), cuya metodología se basa en el sistema de clasificación bibliográfica inventado por Melvil Dewey en 1876 y que dio origen a la Clasificación Decimal Universal, creación de estos dos documentalistas belgas.

En España, fue a finales de los ochenta cuando López Yepes aportó su conocimiento a la disciplina, y más recientemente, explicó que la documentación no se entiende sin su objeto de estudio que está dado por la información, siempre y cuando ésta forme parte de un documento. (López Yepes, 2015, p. 131). Todo esto llevó a crear centros de documentación, que se diferenciaron de las bibliotecas y de los archivos por sus contenidos ecuménicos y universales, en contraste con los de carácter más limitado de estos últimos. El primer caso que se conoce en América Latina es el Centro de Documentación Jaime Torres Bodet creado en el entonces Centro Regional de la Habana y transformado en la Oficina Regional de la Habana en el año de 1959. Esta institución tiene el objetivo de organizar y difundir información sobre las culturas latinoamericanas y caribeñas. Ha llevado a cabo importantes trabajos como la creación y desarrollo del Sistema de Información Cultural de América Latina y El Caribe (SICALC) y la creación del Tesauro Internacional de Desarrollo Cultural, por mencionar algunos de sus trabajos más destacados (Dorta-Duque \& Patallo E., 2009, p, 5).

En Europa y, particularmente, en España, se creó en los años noventa el Centro de Información y Documentación Científica (CINDOC) producto de la fusión del Instituto de Información y Documentación en Ciencia y Tecnología y del Instituto de Información y Documentación en Ciencias Sociales y Humanidades que venían funcionando desde el año 1975, y es quizás el más grande en su género hasta nuestros días. Su actividad 
fundamental se ha centrado en la docencia, la investigación y los servicios documentales en general, pero todo ello con la visión común de recopilar y difundir la bibliografía publicada en revistas científicas españolas en todos los campos del conocimiento.

Existe una línea muy delgada entre la concepción de un centro de documentación, un archivo y una biblioteca. El Archivo se refiere al espacio físico que alberga un conjunto de documentos de cualquier fecha, soporte o procedencia, a la institución responsable de su custodia y tratamiento y el edificio donde se llevan a cabo estas labores (Cruz, 1994). De acuerdo con Peiró (2001), el archivo debe satisfacer una triple función de beneficios y usuarios. Las funciones son administrativas, culturales e informativas en tanto que los usuarios son los administrativos, los investigadores y los ciudadanos. Por los alcances de este documento, quizás interesa profundizar en el archivo como lugar que resguarda los documentos.

En la actualidad, la concepción física del archivo también se compone de un inmueble tripartito de zonas para la conservación de documentos (espacios cerrados), de lugares de trabajo para los archivistas (semiabiertas) y de espacios para el servicio de los usuarios (públicos 0 abiertos). Esta noción contemporánea, muy diferente a la de los archivos de la antigüedad, está influida por la producción documental creada principalmente desde mediados del siglo XX con la aparición de nuevos soportes documentales, la aplicación de nuevas tecnologías para el tratamiento y el acceso a los documentos y de mayores usuarios (Peiró, 2001). De ahí que las necesidades constructivas del inmueble requerido para un archivo deban considerar esas tres funciones y las nuevas posibilidades de tratamiento y acceso a los documentos.

Con respecto a la diferencia entre centro de documentación y biblioteca, aunque hay quienes defienden que comparten características demasiado similares, hay quienes opinan que se trata de dos unidades de información diferentes, cada una con sus objetivos, sus funciones, sus contenidos y su finalidad. Otlet (Lelis, 2002), dejó muy claro el carácter limitativo e inflexible de la bibliotecología y su objeto de estudio justificado desde la fundamentación epistemológica y acogido por las corrientes positivistas de su época: la necesidad de crear una ciencia más amplia capaz de reconocer a todos los documentos que registran la actividad humana. Esta sola idea significa que un centro de documentación y una biblioteca no pueden ni deben ser lo mismo en virtud de sus contenidos, de sus funciones y de sus finalidades, por lo tanto, todos aquellos que los posicionan en un ámbito de iguales condiciones, muy probablemente están equivocados. En lo particular, este documento se adhiere a esta última propuesta, justo por las particularidades que caracterizan a uno y a otra.

Aunque no se mencionan aquí las diferencias entre ambas instituciones documentales, si se analizan las características de los centros de documentación: definición, funciones, contenido y finalidad para entender si el Centro de Documentación Presidente Adolfo López Mateos de la UAEMéx cumple con las características de esta unidad de información, de lo contrario, proponer los elementos que lo deberían caracterizar como el centro de documentación más importante de esta institución educativa. Con respecto a su definición, son diversos los autores que se han aventurado a definir al centro de documentación, pero todos los aportes dados hasta la fecha coinciden con la delimitación teórica de Ros que fue recogida en 2002 por Abad en la que se señala que es una: "unidad de información que se dedica al análisis o descripción del contenido de los documentos y la difusión de la información...[su importancia se debe al] alto nivel de especificidad de la información que contienen" (Abad, 2002, p. 208).

$Y$ es que, en efecto, el centro de documentación se entiende como aquella unidad documental encargada no sólo de la recopilación de materiales sobre un área en lo particular, sino que, además, esos insumos le sirven al mismo tiempo para retroalimentación y para generar nuevo conocimiento. De allí que estas instituciones deberían coadyuvar para que haya una transición hacia las sociedades de la información y del conocimiento en cualquier país. En segundo lugar, la función de la Documentación como disciplina científica es documentar. López Yepes decía al respecto que: "la función de documentar significa informar al modo documentario" (López Yepes, 2015, p. 131). Por lo tanto, en un sentido amplio, el centro de documentación, visto como el objeto a través del cual se socializa la "función de documentar" tiene como misión fundamental la de informar a la manera en cómo lo hace la documentación, esto es, incorporando un 
mensaje a un soporte material que dará como producto un documento en una primera fase y transmitiendo ese mensaje para comunicar algo en una segunda fase.

Se puede, sin lugar a dudas, importar conocimiento, pero con ello, se estaría fomentando el consumo de información más no la producción de ella y es justo en la producción -que no consumo en el sentido más mercantil del término- que se encuentra el verdadero sentido de la existencia de esta unidad documental. Así, el centro de documentación tiene la misión de apoyar a los investigadores facilitándoles la información completa sobre los temas de su interés a través de un servicio especializado que incluye el análisis documental. Para lograr el cometido de informar el ser documentado, es decir, el documento que contiene información es necesario realizar lo que los documentalistas denominan análisis documental. El análisis documental es un conjunto de operaciones intelectuales que buscan describir y representar los documentos y la información contenida en ellos de forma unificada y sistematizada para facilitar su control y recuperación. Pero su misión no termina allí, sino que trasciende hacia la generación de nuevo conocimiento. Este método sistemático comprende un procesamiento analíticosintético que va desde la descripción analítica del documento, e incluye su clasificación y catalogación, hasta la construcción sintética por medio de índices, traducciones, reseñas y resúmenes.

Este proceso de análisis documental se da en función de las necesidades de los usuarios que pueden ir desde los que buscan saber qué se está escribiendo en sus respectivas áreas de conocimiento, los que requieren sólo segmentos de información 0 , los que necesitan saber todo lo que se ha escrito en un área en particular. Estas diferentes expectativas han llevado a los especialistas a crear métodos de recuperación informativa más elaborados. Uno de los elementos que los caracterizan es su adscripción a un centro de investigación, de enseñanza o empresarial, lo que facilita la configuración de cuerpos académicos y redes de investigación. Es así como los centros de documentación ofrecen un servicio personalizado y especializado en una determinada área del saber.

También, tienen entre sus ocupaciones la producción bases de datos a través de las cuales se puedan observar, analizar y evaluar factores tales como la cobertura documental, la distribución temática, el análisis documental, los lenguajes de indización y las colaboraciones externas, entre otros. Rubio resumiría que los centros de documentación tienen como principal actividad analizar el contenido de los documentos con base en la significación o contexto que implica las técnicas documentales de indización y resúmenes y no la simple elaboración de inventarios documentales, como lo harían las Bibliotecas (Rubio, 2004). En tercer lugar, es preciso referirse al contenido. Como ha quedado de manifiesto, los centros de documentación constituyen un repositorio ecuménico sobre un área del conocimiento en particular, es decir, son una unidad de información especializada en un segmento del saber universal. Su contenido es producto de la gestión institucional, pero también de la propia producción generada por los investigadores que lo nutren y que al mismo tiempo se nutren de sus contenidos, fomentando con ello la investigación científica.

Ma. Cruz Rubio, Ángeles Maldonado y Claire Fages (Rubio, Maldonado \& Fages, 1992) enlistaban en uno de sus estudios las características que poseen los documentos conservados en estas instituciones. Decían, en primera instancia, que la forma de los soportes documentales que están contenidos en ellos incluyen una gama variada que va desde los tradicionales libros hasta los documentos electrónicos, pasando por fotografías, audiovisuales, entre otros. Los niveles de obsolescencia son, por tanto, evidentes, pues lejos de realizar prácticas de descarte, como lo haría cualquier biblioteca, su misión es la de ser una institución acumulativa de materiales documentarios. Esta cualidad de acopio, aunada a la dispersión y la variedad temática que prolongan la vida media de las publicaciones científicas, trae por añadidura la incapacidad de localizar de manera eficaz la información solicitada por los usuarios, por lo que el documentalista se enfrenta a un reto mucho mayor que el del bibliotecario en cuanto al diseño y uso de sistemas de información y bases de datos eficientes que permitan recuperarla en tiempos cortos.

Todo esto sin considerar que, a mayor volumen de información, mayor será la necesidad de utilizar un número más elevado de fuentes documentales por parte del investigador, lo 
que repercutirá en un mayor costo económico. Por otra parte, la investigación realizada en ellos, lejos de tener un alcance internacional, se vuelca más bien hacia el terreno nacional y, en algunos casos, en el local. Esto provoca que el uso de los tesauros internacionales y plurilingües sea de uso descartado, razón por la cual deben crear sus propias herramientas de control como los índices, los resúmenes y los tesauros. En este sentido, entonces, indizar es extraer una serie de conceptos que responden a los temas tratados en los documentos y que servirán como puntos de acceso para la recuperación de estos. Resumir es representar de forma abreviada, precisa y objetiva el contenido de un documento original. En tanto que los tesauros son se definen de la siguiente manera.

un vocabulario controlado de descriptores con un significado previamente establecido y cuyo fin último sería el de definir de manera unívoca el contenido de un documento. El fin último de este lenguaje es el de ser puente de conexión entre los usuarios y las unidades de información, esto es, de servir tanto para la indización como para la recuperación documental (Martínez, 2010: 7).

Y, por último, la finalidad de los centros de documentación es lograr que los usuarios accedan a una rápida, eficaz y pertinente recuperación de la información, sobre todo en la era digital en la que la información fluye por medios electrónicos cada vez más ágiles, de mayor cobertura, con una mayor imparcialidad, pero también con una carga de ligereza, fugacidad y de contenidos efímeros. En resumen, estos centros son unidades documentales con un alto nivel de especialización que se crean con el ánimo de generar información y conocimiento en cualquier sector poblacional, ya sea académico, gubernamental o empresarial, preferentemente desde el terreno local. Dicho esto, el Centro de Documentación Presidente Adolfo López Mateos de la UAEMéx debería enfocar su misión bajo esta perspectiva.

Ahora bien, una vez aclarado el contenido que debe poseer esta unidad documental, es necesario referir también las características del continente, esto es, los elementos del edificio, sea éste una construcción nueva, habilitación de un espacio, o bien, la restauración y reciclaje de un área previamente destinada para este fin. En el caso del centro de documentación, se llevó a cabo este último proceso, es decir, se restauró y se recicló un área del actual edificio de Rectoría pero, ¿en qué consistieron estos procesos? Antes de explorar la metodología que se empleó para ello, se describe el funcionamiento del Centro de Documentación de la UAEMéx.

\section{Centro de Documentación Presidente Adolfo López Mateos: breve descripción}

Como se anota en la introducción, Ros (1996) señala la importancia de la planificación para el correcto funcionamiento de un centro de documentación y, en particular, destaca el periodo previo a la creación (Martin, 1987 citado en Ros, 1996). En esta fase es fundamental captar el interés de los futuros usuarios (a través de la organización de eventos sobre el fondo documental dispuesto previa encuesta realizada a los interesados), el acondicionamiento del inmueble (que incluye la compra del mobiliario oportuno, la reorganización de los fondos documentales y los soportes para estos) y la selección y reclutamiento del personal.

No obstante, como se señaló anteriormente, en México no existe una normativa constructiva que delimite a los centros de documentación, lo más cercano a ello es la construcción de las bibliotecas en el territorio nacional, de hecho, Mireles \& Arellano (2015) señalan que poco se conoce sobre la evolución de los procesos constructivos, las características que tienen las bibliotecas y el impacto en los usuarios y trabajadores. Ambos autores señalan que tanto el Reglamento de Ley que crea al Comité Administrador del Programa Federal de Construcción de Escuelas, como el Reglamento de Seguridad, Salud y Medio Ambiente de Trabajo son los entes reguladores que deben guiar la realización de estudios, proyectos, construcción e instalaciones y funcionamiento de los espacios educativos nacionales. Con respecto a la restauración de inmuebles para la oferta de servicios bibliotecarios con edificios de valor histórico es la Ley Federal sobre Monumentos y Zonas Arqueológicos, Artísticos e Históricos la que regula la protección, 
Figura 1a. (Izquierda) Museo de Historia Natural de la UAEMéx: división en mezzanine. Fuente: Velázquez, 2014. Fuente: Velázquez, 2014. Figura 1b. (derecha) Museo de Historia Natural de la UAEMéx: interiores.

Fuente: Velázquez, 2014
Figura 2a. (Izquierda) Centro de Documentación de la UAEMéx: interior.

Fuente: Dirección de Museos, UAEMéx, 2020.

Figura 2b. (derecha) Centro de Documentación de la UAEMéx: fondo de documental.

Fuente: Velázquez, 2014
$1 \quad$ El inmueble está clasificado como monumento histórico por parte del Instituto Nacional de Antropología e Historia. conservación, restauración y recuperación de inmuebles históricos destinados a la educación (art. 36, fracción I).

Es importante considerar porque la UAEMéx inauguró el Centro de Documentación Presidente Adolfo López Mateos en el año 2018 en un espacio ubicado en el edificio histórico de la Rectoría universitaria. Este edificio histórico es un inmueble del siglo XIX al cual fue necesario realizar un trabajo de restauración y reciclaje de los espacios para albergar al centro de documentación. El edificio de Rectoría se erige sobre las ruinas de una casona del siglo XVIII conocida como el Beaterio de Toluca de origen virreinal. En el siglo XIX se estableció el ICLA, que hoy se ha convertido en la UAEMéx. Aunque las actividades académicas ya no se desenvuelven en este ícono histórico, este sigue siendo el núcleo de la universidad. Por ello, las restauraciones e intervenciones son constantes en este espacio para su conservación y evitar la pérdida patrimonial ${ }^{1}$.

La propuesta ejecutiva para la construcción del centro de documentación se originó de la necesidad de acoger la documentación histórica universitaria, pero también como resultado de la donación que realizó la familia del expresidente mexicano a las autoridades universitarias. De ahí que se destinara un espacio -que antes alojaba al museo de Historia Natural de la institución- a un costado de la entrada principal del edificio (véase figura 1a y $1 \mathrm{~b}$ ). Las principales autoridades universitarias fueron las encargadas de solicitar el proyecto ejecutivo, el cual estuvo precedido por un estudio de necesidades de los futuros usuarios del Centro de Documentación.
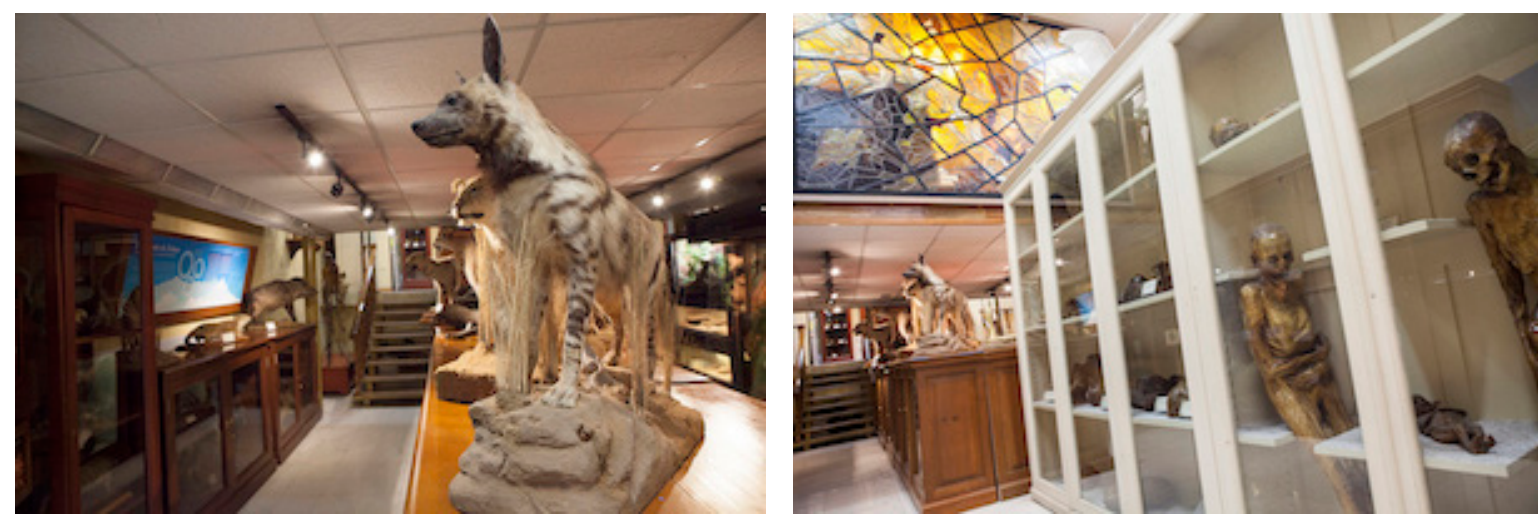

El Centro de Documentación de la UAEMéx está dedicado al resguardo, preservación y difusión del patrimonio documental histórico de la universidad (UAEMéx, 2020). El acervo de este recinto está integrado por dos fondos documentales: el del Presidente Adolfo López Mateos (10,000 volúmenes) y el del Instituto Científico y Literario Autónomo (ICLA) (13,000 expedientes). El primer fondo está integrado por acuerdos y decretos presidenciales, legajos hemerográficos, libros, revistas, reconocimientos, diplomas, fotografías digitales, documentos sonoros y cintas de película (véase figura $2 a$ y $2 b$ ). El segundo fondo se clasifica por las secciones de gobierno, administración, academia y cultura (UAEMéx, 2020).
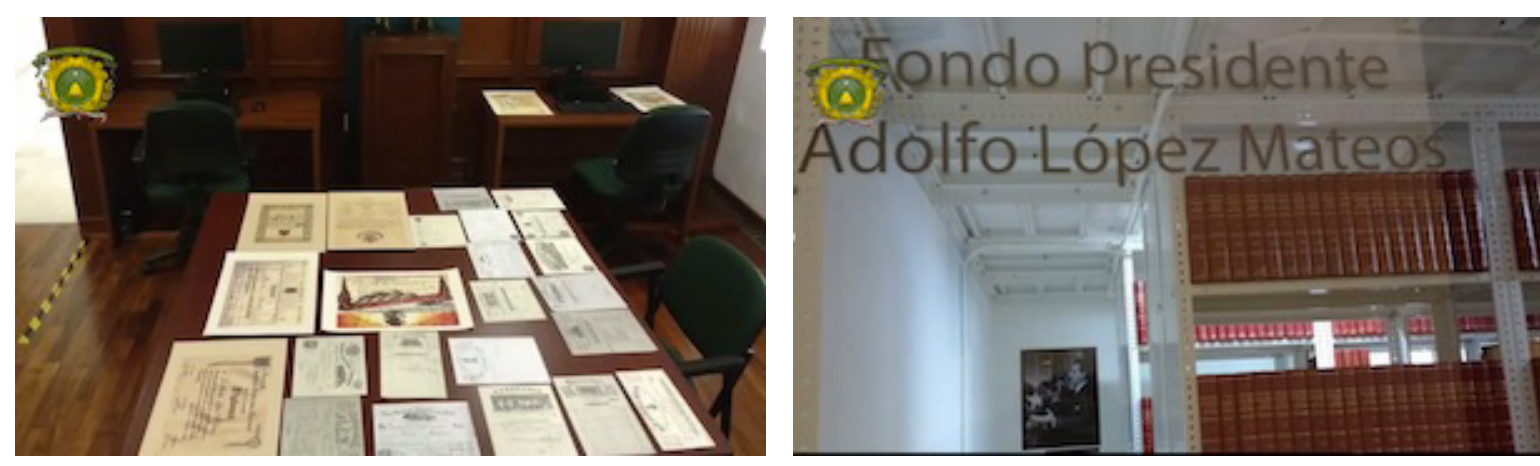

De acuerdo con la propia universidad (UAEMéx, 2020), funciona más como un archivo histórico y aspira a convertirse en un centro de documentación. Actualmente, es una unidad del departamento del Archivo Universitario y dependiente también de la Dirección de Museos de la Secretaría de Difusión Cultural. El organigrama está integrado por un responsable del archivo histórico, un área administrativa, área de procesos técnicos y consulta, área de conservación y restauración y área de coordinación de proyectos. En total, laboran personas con perfiles profesionales de Historia (2), Administración (1) y Artes Plásticas (1) quienes han sido capacitados en temáticas de archivística, conservación documental, manejo de archivos y curaduría. Los servicios que ofrece al público en general consisten en visitas guiadas, consulta abierta a investigadores, académicos y público en general, reprografía bajo las modalidades de fotocopia, facsímil, escaneo o fotografía, servicio social y prácticas profesionales. 


\section{Propuesta para restauración y reciclaje de espacios}

Para llevar a cabo los procesos constructivos del Centro de Documentación Presidente Adolfo López Mateos fue necesaria la elaboración de un proyecto de rehabilitación del espacio que existía. Se emplearon dos propuestas que condujeron al resultado que hoy conforma al edificio, una de ellas fue de restauración, que fue complementada por una sugerencia que implicaba el reciclaje. En este apartado se exponen ambos planteamientos para entender a profundidad las decisiones que se tomaron a lo largo de la ejecución del proyecto. Es preciso comentar que las bases de la restauración clásica las estableció Viollet Le Duc, quien la definió como una intervención científica que se basa en el conocimiento histórico y tecnológico de la edificación arquitectónica.

Brandi (1988) recupera los fundamentos establecidos por Le Duc para aportar un enfoque teórico contemporáneo sobre la restauración. Destaca la necesidad de considerar el estado de conservación de los bienes muebles e inmuebles, los materiales y las tecnologías. En este sentido, la restauración arquitectónica es una intervención especializada fundamentada en el análisis científico y una metodología concreta: "... un sistema ordenado o unidad integrada por materiales, procedimientos constructivos [y] espacios" (Rojas, 2011, p. 31), es decir, un conjunto de principios y fundamentos que apuntan hacia el cumplimiento de funciones específicas (Chanfón, 1988).

Existen diversos planteamientos para la intervención arquitectónica, pero para esta investigación se optó por la propuesta de Chávez y Álvarez (2005) porque considera el diagnóstico de los datos presentes en la edificación a intervenir, la evolución y el pronóstico de desarrollo. De ninguna manera se pretende calificar como la única propuesta de restauración, sino aportar al debate académico la evidencia científica de que este planteamiento puede combinarse con un proyecto de reciclaje. Para proponer una solución que realmente cubra las necesidades de cualquier espacio que vaya a ser restaurado, es necesario un análisis profundo del estado actual del espacio a partir de muestreos con el fin de determinar las condiciones de la estructura y los materiales, para de esta forma aprovechar al máximo los recursos existentes y sin un impacto severo en el presupuesto final de la obra. De igual forma, es conveniente un reconocimiento, levantamiento arquitectónico y de estructuras detallado y sistemático. Además, un análisis de las patologías internas y externas respondiendo al origen, causas, evolución, síntomas y estado actual de cada uno de los espacios para proceder a la terapéutica del inmueble.

Chávez y Álvarez (2005) proponen que se realice la inspección inicial para diagnosticar cualquier falla y el levantamiento de deterioros, cuya utilidad es documentar los daños y patologías existentes en el inmueble. De cada patología debe registrarse: tipo de lesión, descripción, causa, materiales afectados, afectación a la estabilidad estructural, etcétera. Enseguida se evalúa sistemáticamente al inmueble para determinar si existen procesos que deban realizarse con urgencia, como es el caso de las estructuras desde los cimientos hasta las techumbres. Es importante la recopilación de antecedentes del inmueble a restaurar, en ella se deberán obtener documentos que verifiquen su autenticidad, así como las intervenciones que se han realizado anteriormente y su ubicación en una línea de tiempo histórica (Chávez y Álvarez, 2005). En esta fase es recomendable anexar planos, fotografías antiguas y documentación histórica del inmueble. Toda la información recabada deberá plasmarse en fichas detalladas del estado actual y en planos a escala 1:100 / 1:50 de preferencia para observar los daños encontrados con detalle.

Chávez y Álvarez (2005) mencionan que la prueba de prediagnóstico es aquella que establece una hipótesis de las causas de deterioro o de riesgos que pudieran darse en caso de no ser intervenido el espacio. Para ello, se requiere de la selección de análisis especiales, ya sea en sitio o en el laboratorio. Es necesario personal capacitado para realizar los análisis y que conozca la metodología y manejo de herramientas técnicas o científicas para llevar a cabo los posibles resultados. En estos análisis, no se comprometerá la integridad de los elementos, es decir, se trata de pruebas no destructivas. 
La fase de diagnóstico implica la reconstrucción de los hechos que detonaron el proceso patológico que comprenden: las causas directas e indirectas que originaron el problema, la evolución de los daños indicando tiempos, periodicidad, transformaciones y patologías que se originaron posteriormente por estos daños, los mecanismos de actuación, causas primarias o secundarias que detonaron el daño y el estado actual de la situación del proceso. Con base en esa fase se realiza el pronóstico para prevenir la evolución de los daños, seleccionando los procedimientos adecuados que en etapas siguientes se realizarán. Si el pronóstico no es favorable, se buscarán alternativas técnicas, desde la anastilosis hasta la reconstrucción. No obstante, en caso de afectación mayor, si se convierte en un peligro para la vida de los usuarios como el caso de un gran terremoto o actividad de guerra, deberá demolerse la edificación.

En la fase de la terapia, señalan Chávez y Álvarez (2005), se efectúan las propuestas de intervención previamente establecidas y cuyo objetivo es restablecer la funcionalidad del edificio. Posteriormente comienza el periodo de ejecución, para lo cual se requiere de la mano de obra capacitada y especializada en labores de conservación. Se llevará un control de toda la ejecución, desde el inicio hasta que finalice la obra para corroborar que la calidad de los trabajos sean los contemplados, mediante una bitácora técnica donde sea posible corroborar cada una de las etapas de obra, hasta su entrega. Una vez realizada la ejecución se procede a la evaluación de los resultados finales para observar la aceptación de los nuevos materiales con los originales y validar si las decisiones tomadas en el diagnóstico fueron las más adecuadas. Finalmente se entrega un manual de mantenimiento, es decir, las acciones que permitirán la prolongación del ciclo de vida del inmueble y su funcionamiento.

Deben contemplarse revisiones periódicas a las estructuras, instalaciones y arquitectura de interiores y exteriores, así como la limpieza del sitio. Al finalizar, todas las intervenciones hechas, las acciones realizadas deberán formar parte de un expediente técnico que permita revisarse por parte de las instituciones encargadas de la salvaguarda del patrimonio de cada entidad.

El reciclaje arquitectónico surge como una respuesta a la necesidad de un inmueble cuando está en riesgo porque su funcionamiento ha dejado de ser rentable, es obsoleto o está siendo abandonado. Tanto reciclaje como restauración son términos muy cercanos en la práctica arquitectónica (Martínez, 2012). Mientras que en la primera se utiliza de forma contemporánea guiada por un proceso de sostenibilidad, la segunda ha sido empleada históricamente como una forma de intervención y conservación para las edificaciones, por tanto, las bases del reciclaje están sustentadas en la restauración.

Sin embargo, desde principios del siglo XXI, Latham (2000) utilizó el término reutilización creativa y el objetivo de ese proceso era revivir antiguos edificios y garantizar su existencia, mediante la transformación, pero preservando el valor histórico. Druot, Lacanton \& Vassal (2007) enfatizan en la transformación y empleo continuo, a partir del reaprovechamiento de los elementos existentes en las edificaciones del pasado. Braungart \& McDonough (2005) consideran al reciclaje arquitectónico como un nuevo ciclo de vida a los elementos que son susceptibles de intervención. En el caso particular de McDonough es quizás de los primeros en apuntar hacia la sostenibilidad, en cuanto a la eficiencia energética y la conservación medioambiental.

Como se mencionó en el caso de la restauración, también existen diversas propuestas que sugieren la guía para el proceso de reciclaje, pero esta investigación se considera el planteamiento de Navarro (2016) por considerar los elementos clásicos que sostienen los principios del reciclaje arquitectónico. Por tanto, se afirma que el reciclaje es una solución sostenible que se apoya de lo existente dentro de lo contextual, material y social. Para que el éxito del proyecto sea viable, es necesaria la planeación de una estrategia que responda a los objetivos propuestos durante la planeación del proyecto y que, a su vez, sea coherente a nivel urbano, económico y social en el entorno en que será trabajado. La propuesta deberá permitir su transformación en el futuro y será perceptible y entendible por los usuarios.

A continuación, se desglosan cuatro puntos que conforman a la propuesta de reciclaje de edificios (Navarro, 2016). La primera consiste en concebir al espacio como un vacío que puede transformarse, apoyándose de los recursos disponibles, lo cual implica una 
observación cualitativa o cuantitativa, la recuperación o regeneración de la identidad del espacio, el acercamiento al usuario y sus cambiantes necesidades y la determinación del impacto generado en el usuario para visualizar el éxito o continuidad del proyecto.

La segunda fase, menciona Navarro (2016), requiere entender la arquitectura a partir del legado existente. La propuesta tiene como objetivo no derribar, o bien, reutilizar lo derribado para aprovechar la disponibilidad del espacio. Para ello se requiere de la innovación a la hora de mejorar los resultados anteriores, la reutilización de materiales y el empleo de los materiales que se van a derribar. De igual forma, se deberá emplear la normatividad existente para reducir el riesgo de consecuencias negativas e irreversibles.

Una tercera etapa del reciclaje conlleva la reprogramación del espacio arquitectónico para nuevas formas de uso, funcionalidad y adecuación del espacio. Las formas de uso es la valoración de la utilidad y distribución del espacio, la funcionalidad está determinada por una estrategia y la compatibilidad de las instalaciones; en tanto que, la adecuación implica que los nuevos refuerzos empleados sean acordes con la arquitectura, los condicionantes y los recursos necesarios.

Finalmente, el rediseño del espacio es a partir de la materia existente, la creación de nuevos modelos, pero con una visión de sostenibilidad medioambiental, social, cultural y económica. La durabilidad será determinada por la consideración de reciclaje a futuro que considere diferentes ciclos de vida. En esta fase también interviene el espacio intermedio, es decir, el espacio de acción y relación con capacidad de transformarse al interior y exterior (Navarro, 2016). Y el espacio urbano que se vincula con el apropiamiento del usuario del espacio público.

Es imprescindible que en esta etapa se busque el ahorro energético. $Y$, sobre todo, la reutilización de las partes antiguas, la recreación de los signos de la vejez, la superposición rotunda de lo nuevo que son estrategias propias de la creación de un objeto diferente en un mismo espacio.

\section{Resultados}

De los elementos establecidos en cada una de las propuestas descritas, se puede referir de manera general que para el Centro de Documentación Presidente Adolfo López Mateos se consideraron los siguientes elementos:

En primer lugar, hay que señalar que en el año 2018 fue inaugurado el Centro de Documentación Presidente Adolfo López Mateos de la UAEMéx. Para lograr el éxito del proyecto fueron necesarias combinar las metodologías expuestas anteriormente, ya que se hicieron las restauraciones necesarias en el espacio, sin embargo, se modificó el uso. Es decir, el espacio se "recicló". El espacio está ubicado en la fachada norte del edificio de Rectoría sobre la avenida Instituto Científico y Literario del centro de la ciudad. La crujía cuenta con $140.77 \mathrm{~m} 2$ y con $18.29 \mathrm{~m}$ de frente. En las figuras 3a y 3 b se observan la planta arquitectónica de conjunto y la planta arquitectónica del sitio.

En primer lugar, se realizó una visita de inspección inicial donde se tomaron las medidas generales del espacio que fue intervenido. Durante el diagnóstico del espacio, el Dr. Horacio Ramírez de Alba, ingeniero estructurista de la UAEMéx, hizo un estudio de los muros de carga que datan del siglo XVIII y ubicó una losa de entrepiso de concreto armado que no estaba contemplada en el cálculo inicial de los muros de carga antiguos, por lo que se decidió reforzar el interior del espacio del centro de documentación con unos soportes de acero al interior, sin alterar el muro en sí.

Se realizó un estudio que comprendió dos fases: análisis de campo y análisis de gabinete. En el primero, se observaron a nivel arquitectónico y de ingeniería, la patología del espacio y de materiales y estructuras. El segundo consistió en el análisis de fotografías, el estudio matemático de las estructuras y la observación de los daños de materiales de manera visual. El único proceso que se manejó de urgencia fue la estabilización del entrepiso que cubre el espacio del centro de documentación, antes mencionada. De acuerdo con la propuesta explicada (Chávez y Álvarez, 2005), dadas las modificaciones que ha sufrido el edificio a lo largo de tres siglos, es imposible tener un registro de todos los trabajos que se han realizado. Dentro del trabajo técnico, hubo la necesidad de 


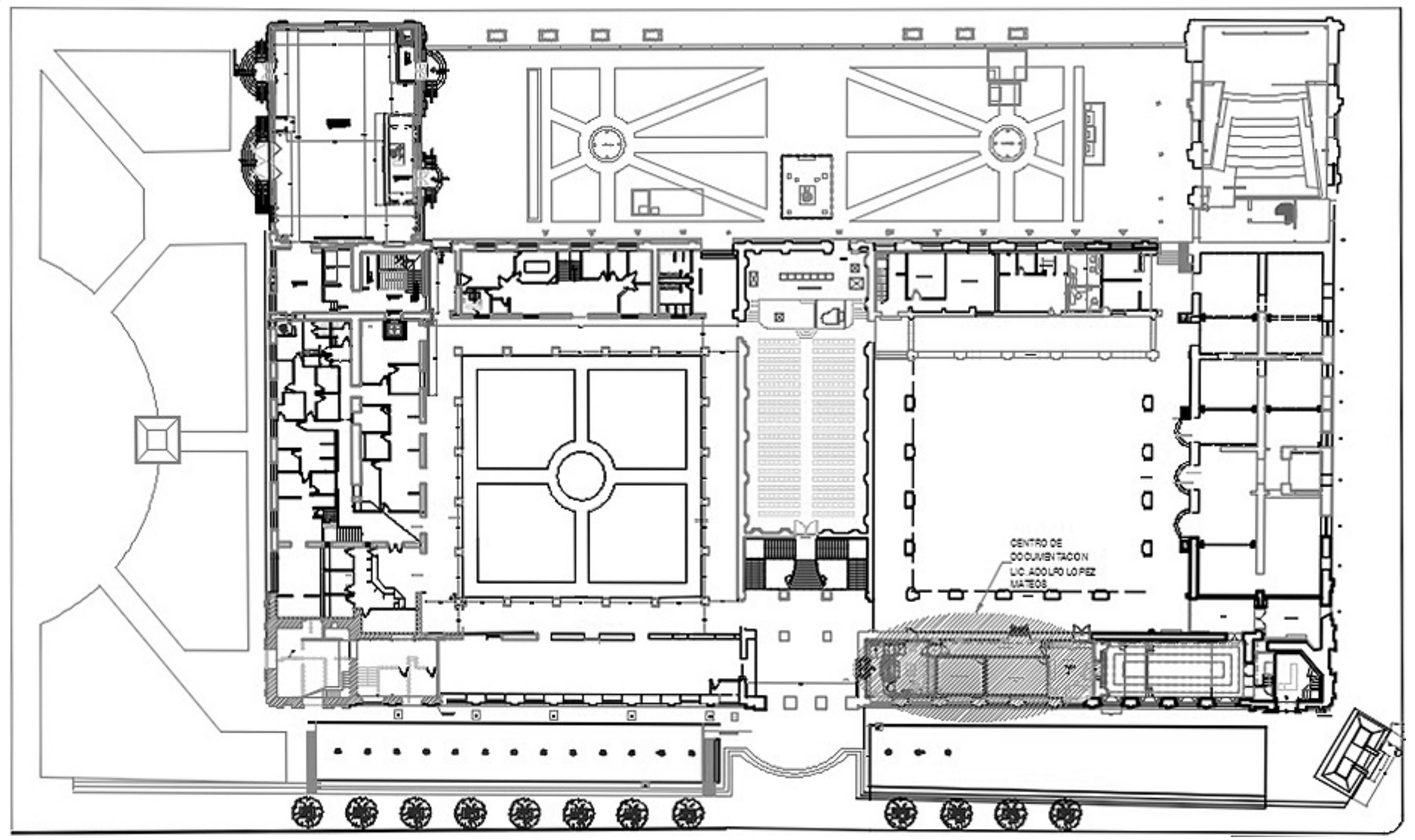

Figura 3a. Planta Arquitectónica de Conjunto: localización del Centro de Documentación Presidente Adolfo López Mateos.

Fuente: Dibujo del Arq. Miguel Ángel Morales F.

Figura 3b. Planta Arquitectónica del Espacio destinado al Centro de Documentación Presidente Adolfo López Mateos.

Fuente: Dibujo del Arq. Miguel Ángel Morales F.

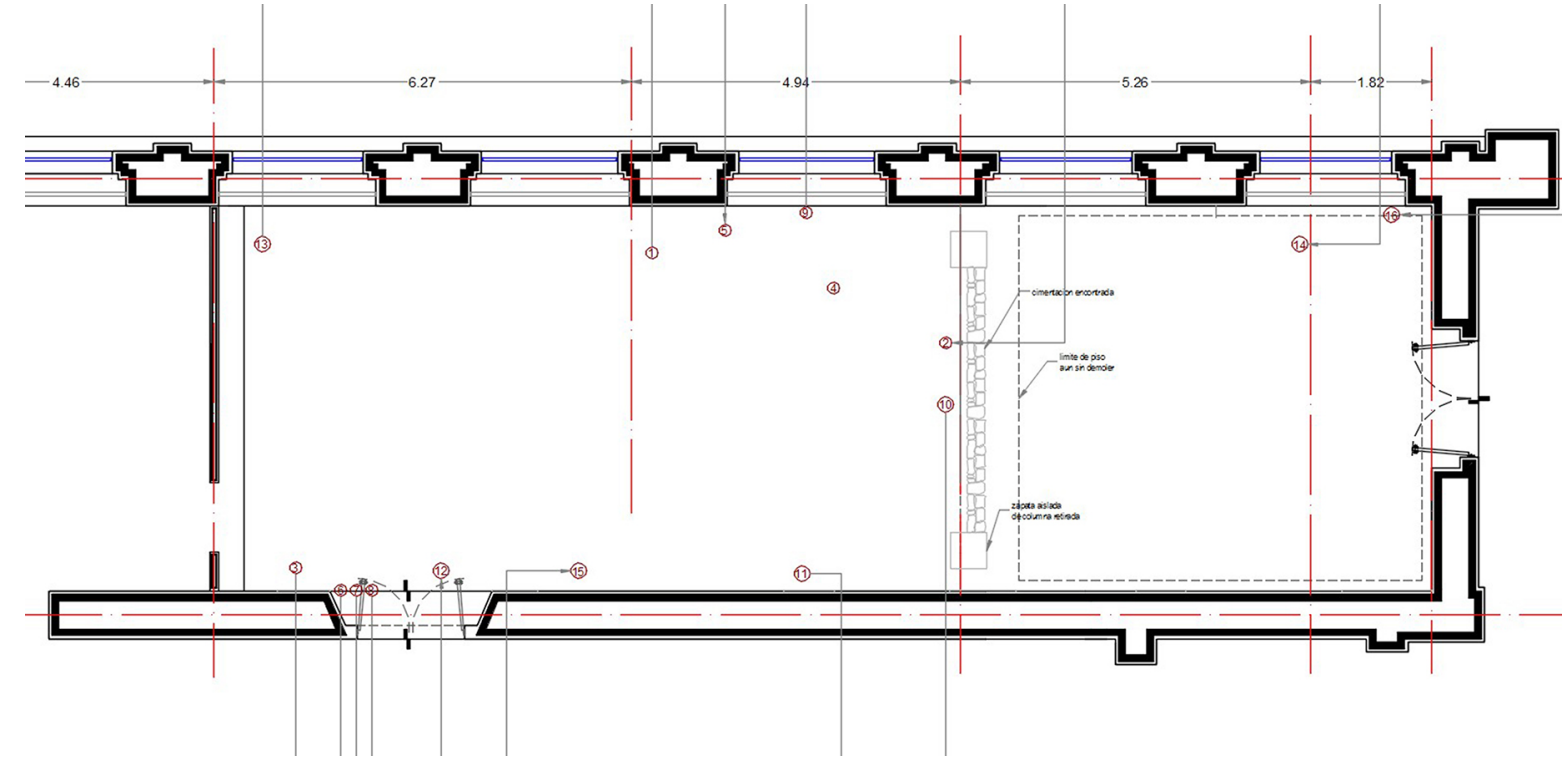

realizar planos, fotografías y algunas lecturas de la historia del inmueble.

En seguida se realizó la observación directa de las estructuras, su comportamiento y su grado de deterioro y con el apoyo de un estudio digital que comprendió las cargas de servicio a las que está sujeto el espacio, es decir, pruebas no destructivas (Chávez y Álvarez, 2005), con base en calas en muros de carga y pruebas de subsuelo donde se observaron los cimientos antiguos del inmueble.

De acuerdo con el proceso patológico (Chávez y Álvarez, 2005), se determinaron varias causas de deterioro del espacio arquitectónico a utilizar, entre las que destacaron: el sobrepeso al cual se ha sometido el edificio, la modificación del espacio con otros sistemas estructurales a lo largo de casi tres siglos y la superposición de varias estructuras por encima de aquellas del siglo XVIII. En la fase terapéutica (Chávez y Álvarez, 2005), que coincidió con el inicio de las labores de construcción, la tecnología original del inmueble, es decir de tierra, fue considerada como prioritaria a partir del empleo de materiales de adobe, tabique y cal. Estos materiales aparecen en los muros de carga del espacio (véase figura 5a).

Posteriormente, realizadas las primeras actividades de obra, fueron encontrados vestigios arqueológicos y paleontológicos que, por norma del INAH, es necesario documentar y entregar para ser estudiados y autentificados. En el muro sur de la crujía, al retirar los aplanados y elementos contemporáneos, fueron localizados unos arcos de 


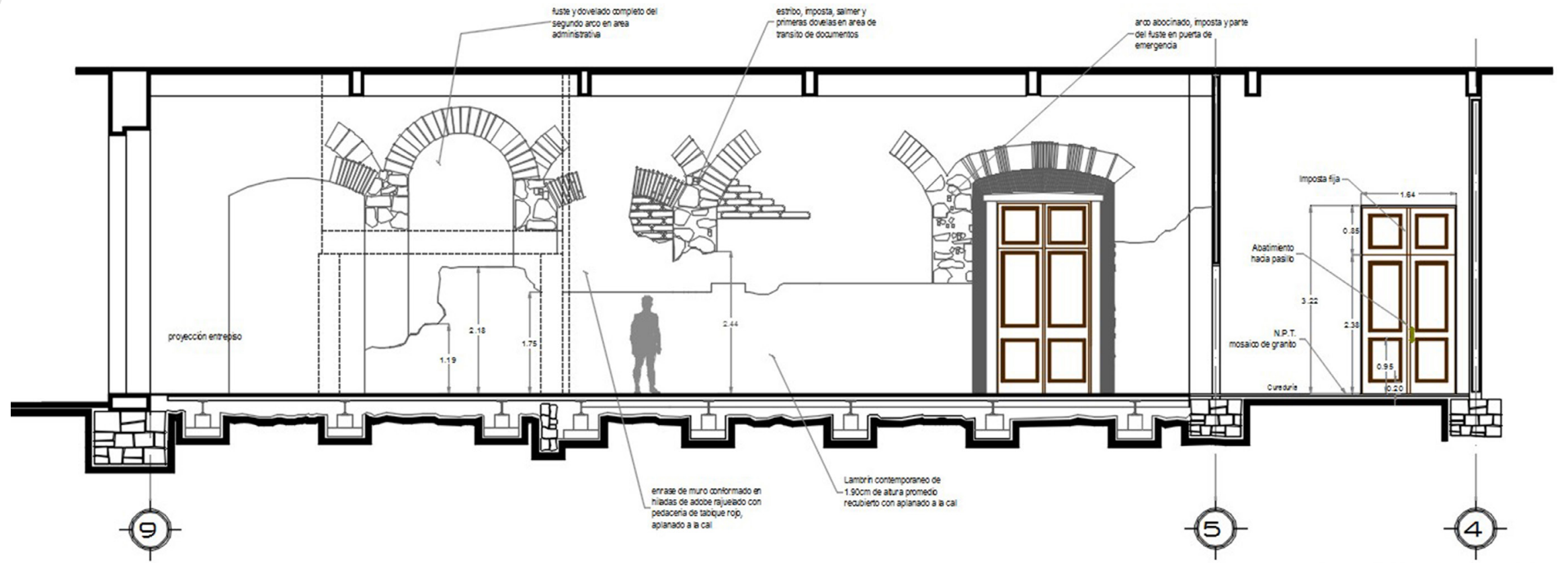

SECCION LONGITUDINAL

VENTANAS ARQUEOLOGICAS

Figura 4. Sección del Espacio destinado al Centro de Documentación Presidente Adolfo López Mateos.

Fuente: Dibujo del Arq. Miguel Ángel Morales F.
Figura 5a. (izquierda) Fase terapéutica del edificio histórico de Rectoría.

Fuente: Arq. Miguel Ángel Morales F.

Figura 5b. (derecha) Preparación para el reciclaje del espacio

Fuente: Arq. Miguel Ángel Morales F.

Figura 5c. (izquierda) Reprogramación del espacio arquitectónico.

Fuente: Arq. Miguel Ángel Morales F.

Figura 5d. (derecha) Elementos de sostenibilidad del espacio.

Fuente: Arq. Miguel Ángel Morales F.
A medio punto y un gran arco abocinado original, que se cree, formaban parte del acceso a una capilla en la antigua casona del siglo XVIII, correspondiente en el tiempo a la Nueva España. Estos arcos también fueron conservados como ventanas del tiempo como se aprecia en la figura 4.

Actualmente, se trabaja en el manual de mantenimiento del espacio que ocupa el centro de documentación, el cual permitirá la continuación de su ciclo de vida. Sin embargo, todo el proceso de restauración y reciclaje está contenido en la bitácora electrónica de la obra, que se localiza en el Departamento de Conservación del Patrimonio de la universidad.

Con respecto al reciclaje del inmueble (Navarro, 2016), desde el inicio del proyecto arquitectónico se pensó en eliminar todos los materiales invasivos que se le impusieron al espacio en el siglo XX. En ese periodo se colocaron muros divisorios, pisos de concreto, estructuras y armaduras de acero que conformaban el Museo de Historia Natural (véase figura $5 b$ ). Con la eliminación de estas estructuras invasivas el espacio se dejó totalmente vacío y se observó la naturaleza del subsuelo, de los muros y la escala derivada de las proporciones de la arquitectura histórica.

Dentro del proyecto arquitectónico, la idea principal fue colocar elementos divisorios de materiales actuales -como perfiles de acero y paneles- que fueran efímeros para no agredir los espacios del siglo XVIII y XIX (véase figura $5 \mathrm{c}$ ). En una tercera fase (Navarro, 2016), el espacio se proyectó a partir de la valoración de la función y la utilidad implícita en la gran escala geométrica que presenta la crujía, por lo que se programaron diferentes zonas con simpleza en el manejo de trazo y en consideración a la arquitectura antigua.
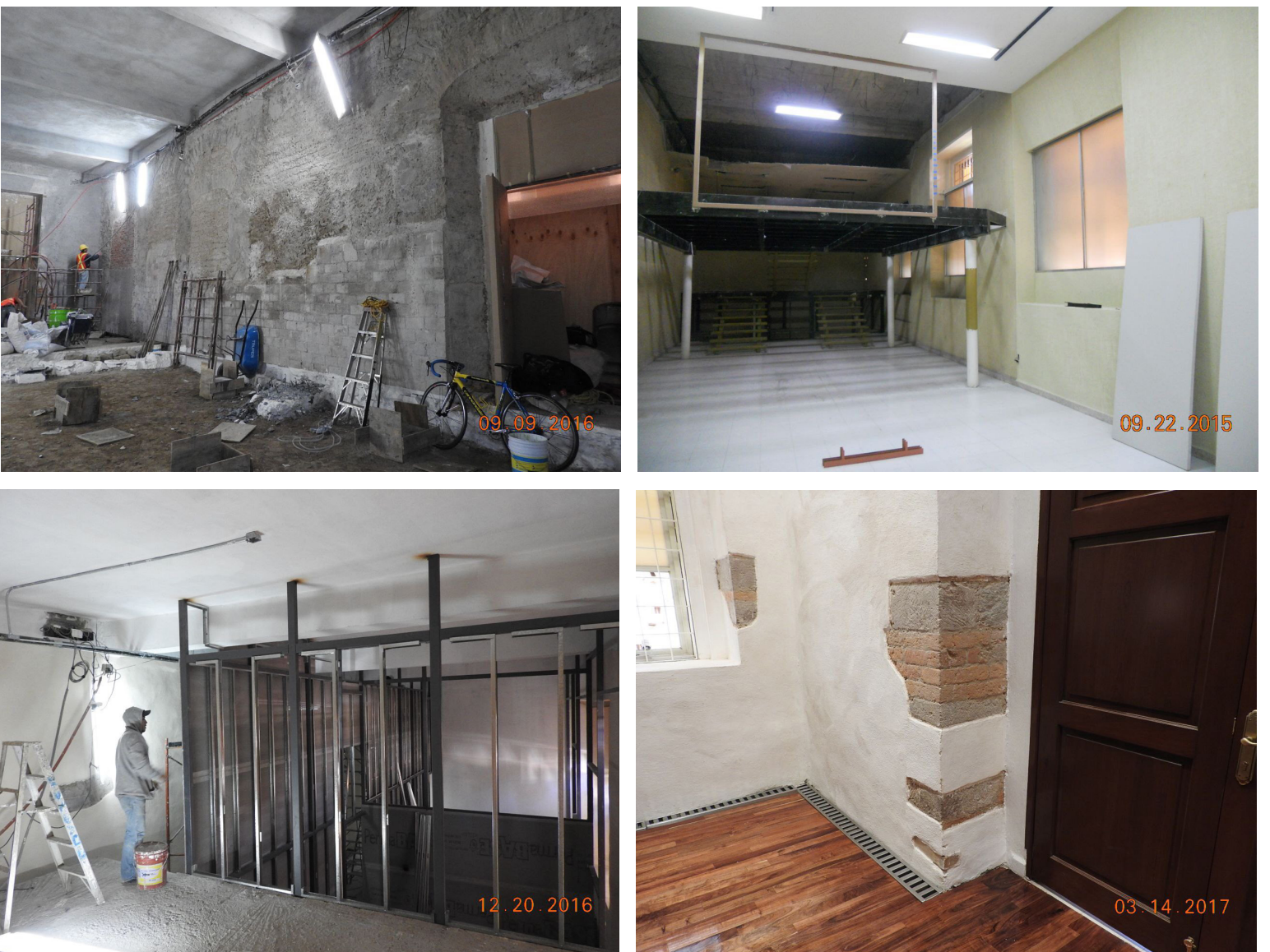

REVISTARQUIS | VOL. 10, Num. 1 (Enero-Junio 2021) | ISSN 2215-275X | San José, Costa Rica | pp. 79-95 
Finalmente, se tomó en cuenta la sostenibilidad del edificio en el pasado con la colocación en el subsuelo de cámaras de aire que existieron antiguamente (véase figura $5 \mathrm{~d}$ ). Asimismo, los aplanados se rehicieron con la tecnología de la cal, lo cual permitió la respiración de estas estructuras, como la del muro sur que soporta una carga extraordinaria de 60 toneladas. El muro contiene las arquerías arqueológicas anteriormente mencionadas, dichas arquerías no son susceptibles de modificación por su antigüedad y memoria estructural. Una vez concluido el rescate del espacio, a partir de las tendencias de restauración y reciclaje, se procedió a la inclusión de la infraestructura y el equipamiento. Con los materiales retroactivos, fue necesario crear dos grandes cápsulas que contienen los dos acervos documentales por separado. Estas cápsulas son el elemento fundamental del proyecto y en su interior se encuentra una serie de estanterías de marca Remington, especializada para centros de documentación y archivos.

Las cápsulas están divididas en una planta alta y una planta baja para acomodo y clasificación de los fondos documentales, según las necesidades de la unidad documental. Las cápsulas están reguladas en su climatización y humidificación para la conservación de los documentos. El ingreso al recinto se permite a través de dos grandes portones que se localizan en el vestíbulo principal del acceso al edificio de Rectoría. Posteriormente, dentro de un pequeño vestíbulo se encuentra la recepción del inmueble, que está decorada con un busto del expresidente. En seguida se encuentra el espacio destinado a la consulta de documentos por parte de los usuarios, el cual está equipado con computadoras y escáneres. En la parte superior de la zona de consulta se localiza la secretaría, la administración y la jefatura del centro de documentación (véase figura 6).

Un pasillo en el interior, con acceso limitado, permite la entrada a ambas cápsulas. Al final de este espacio se localiza el área de conservación y de curaduría de los documentos que se localizan en el lugar.

Debido al carácter histórico y patrimonial del edificio, las instalaciones eléctricas se realizaron de forma externa para el mantenimiento y seguridad del espacio en caso de incendio. Las instalaciones incluyen la transmisión de banda ancha y cámaras de seguridad, dentro y fuera de las cápsulas. Como se observa, los planteamientos utilizados para la instrumentación del Centro de Documentación Presidente Adolfo López Mateos fueron de gran utilidad para obtener un conocimiento más profundo sobre las condiciones estructurales del espacio, por lo que su aplicación se puede replicar en obras de similares condiciones.

Figura 6. Volumetría tridimensional del Centro de Documentación de la UAEMéx. Fuente: Arq. Miguel A. Morales F.
Lo expresado hasta aquí permite tener una mayor claridad de lo que debería ser el centro de documentación estudiado, por lo que en el siguiente apartado se describe la configuración final de esta unidad documental tan relevante para la Universidad Autónoma del Estado de México.

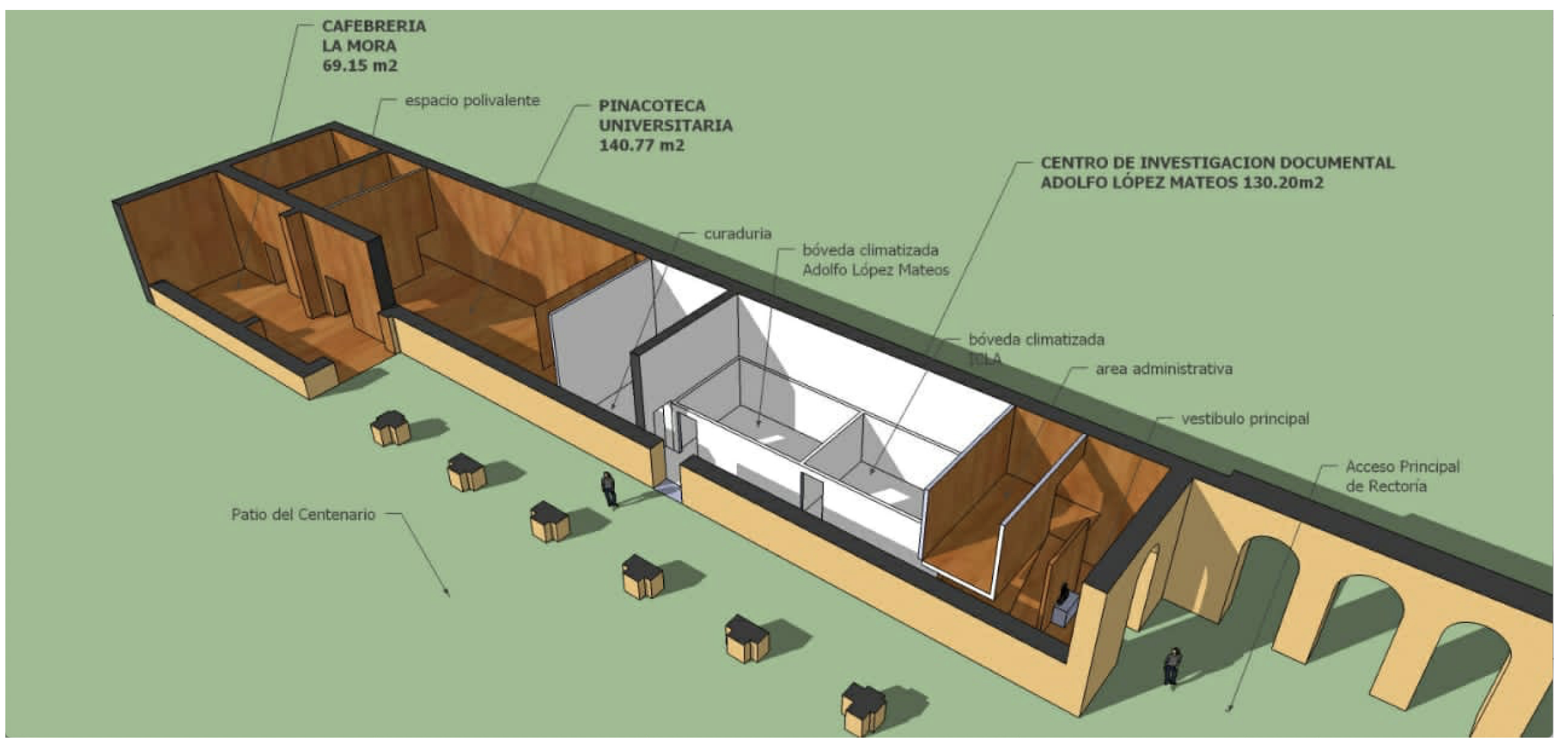




\section{Discusión: conservación y reciclaje para la creación del Centro de Documentación Presidente Adolfo López Mateos}

Los centros de documentación han sido por mucho tiempo unidades documentales poco entendidas por la sociedad a pesar de la riqueza de contenido que poseen derivado de la acumulación informativa generada a lo largo del tiempo. Hay que recordar que no son bibliotecas portadoras de un conocimiento ecuménico y de utilidad generalizada, sino centros especializados en temas particulares de investigación (Abad, 2002). Por lo tanto, la información y documentación científica que se produce sobre algún tema en particular, en los contextos nacional e internacional, debería estar accesible a los investigadores y especialistas en la materia. Esta es la premisa inicial de la labor que desempeñan las unidades documentales a las que se ha hecho referencia a lo largo de este estudio.

Sin embargo, este aspecto está lejos de hacerlos ver como unidades limitativas y de privilegio para élites académicas y científicas determinadas. Antes bien, su alto nivel de especificidad temática los hace ser grandes portadores de información y conocimientos desarrollados, lo que hace que haya un mejor entendimiento sobre un problema que aqueja o ha aquejado a la sociedad en general. Tal como lo señala la literatura especializada (Rubio, Maldonado \& Fages, 1992), la Universidad Autónoma del Estado de México poseía una gran riqueza informativa y documental proveniente, y a la vez generada, por el ex-presidente Adolfo López Mateos que se resguardó en el archivo institucional, sin embargo, tras el análisis de sus contenidos se llegó a la conclusión de que este acervo reunía todas las características para pertenecer a un centro de documentación y no a una unidad archivística.

Aunque, como apunta la literatura especializada sobre la funcionalidad de los centros de documentación, se requiere que este recinto universitario contenga una especie de "fondo acumulado" sobre la vida y obra de López Mateos y no solamente la documentación donada por los familiares, de tal manera que evite confundirlo con un acervo archivístico. Esto llevó a la iniciativa de crear un centro de documentación hasta ese momento inexistente en la institución a partir de la restauración y reciclaje de un espacio ubicado en el emblemático edificio de Rectoría. Es en este punto donde se presenta un problema que era urgente resolver: el desgaste natural del espacio derivado de la antigüedad del inmueble.

En el ámbito arquitectónico se emplean dos planteamientos (Chávez y Álvarez, 2005; Navarro, 2016) que permiten diagnosticar y evaluar un espacio que pretende ser utilizado o reutilizado, estos son el método de restauración y el de reciclaje, que obligaban a ser aplicados al centro de documentación. Producto del análisis y aplicación de estos métodos de restauración y reciclaje se observaron problemas estructurales y de la patología de este edificio que data del siglo XVIII, pues desde entonces hasta nuestros días, el inmueble ha sufrido constantes remodelaciones que, por fortuna, no han alterado significativamente su estructura original. El diseño de este centro presentó un reto desde el encargo ejecutivo, el cual consistió en demostrar que era posible un proceso de reciclaje del inmueble y no de superposición de nuevas y fallidas estructuras. De ahí que la metodología de restauración y reciclaje han servido de experiencias exitosas para rescatar nuevos espacios en beneficio del edificio histórico universitario, ya que por un lado se consideró la conservación del inmueble (Brandi, 1988) y, por otro lado, la sostenibilidad de la infraestructura (Braungart \& McDonough, 2005).

Con el rescate del espacio, los trabajos de arquitectura e ingeniería de restauración sobre el inmueble antiguo abren una ventana al tiempo para dar a conocer los restos de una edificación que con anterioridad se aposentó en este sitio. Se trata de un inmueble muy probablemente de tipo religioso del siglo XVIII, por las arquerías localizadas y los materiales originales que los ancestrales alarifes utilizaron en su época. Cada vez que se realiza en el edificio histórico de la rectoría de la UAEMéx un trabajo de conservación, ya sea en muros, pisos o estructuras, se han encontrado múltiples hallazgos que permiten tener una lectura cercana a sus orígenes y establecer una relación con su pasado. De allí que, para salvaguardar la historicidad del inmueble, la estrategia de reciclaje haya incluido, elementos como la instalación eléctrica, los entrepisos, los muros añadidos, 
etcétera que se pensaron como algo efímero, así como la colocación de cámaras de aire en el subsuelo como un elemento de sostenibilidad para el edificio.

\section{Conclusiones}

La función del Centro de Documentación Presidente Adolfo López Mateos de la Universidad Autónoma del Estado de México debería ser constituir y difundir un fondo documental especializado, no sólo producido por la propia institución, sino recabar la procedente de otros organismos académicos, gubernamentales o empresariales y que aborden la vida y obra de este importante personaje que se convirtió en presidente del país. Pero, además, debería recopilar y difundir la producción científica generada no sólo en libros, sino en revistas científicas mexicanas y del extranjero sobre el mismo López Mateos. También, hay que considerar la docencia, promoción de la investigación, acceso a servicios documentales en general y diseño de bases de datos especializadas bajo la misma línea temática.

La configuración del fondo documental debería darse a partir de la elaboración propia del material científico-técnico o de la selección de materiales producidos en otras instancias, con el fin de difundir previamente el análisis documental de sus contenidos. Este análisis documental funge como un reductor de distancia entre las fuentes de información cada vez más abundantes y la limitada capacidad del ser humano para asimilar sus contenidos. La solicitud para crear un recinto que albergará el resguardo de los fondos documentales institutenses y del expresidente crearon la necesidad de reconvertir un espacio universitario. Si bien, no existe una guía específica para la edificación de este tipo de construcciones en México, las metodologías de restauración y reciclaje de inmuebles históricos, así como el trabajo conjunto de especialistas de ciencias de la información y arquitectura, ingeniería y conservación del patrimonio, permitieron proyectar la restauración del centro de documentación universitario.

Finalmente se debe mencionar que el trabajo conjunto de profesionales de la información y de la arquitectura se conjugaron en esta investigación con el fin, por un lado, de reforzar la idea de que un centro de documentación no es lo mismo que un archivo ni una biblioteca, aquel tiene características muy específicas que lo hacen diferentes a los otros dos. En México se debe promover la instauración de éstos en la medida en que la investigación se promueva con mayor ahínco para el logro del bien común. Y, por otro lado, la construcción, restauración o reciclaje de los edificios que los albergarán requieren de métodos específicos, sobretodo cuando se trata de edificios antiguos. En este sentido, estamos a favor de la restauración y más aún del reciclaje, aun cuando algunas teorías establecen que es mejor contar con inmuebles nuevos para la conservación de los documentos antiguos, sin embargo, muchas veces, el presupuesto escapa a las posibilidades institucionales de decantarse por esta opción.

\section{Agradecimiento:}

Los autores agradecen el apoyo técnico del Arq. Miguel Ángel Morales F. del Departamento de Conservación del Patrimonio de la UAEMéx en la elaboración de los planos arquitectónicos y las fotografías.

\section{Referencias bilbliográficas}

Abad G., M. F. (2002). Manual de ciencias de la documentación. Madrid: Pirámide.

Arnau, P. (1995). Trascendencia de la vida y obra de Paul Otlet. Revista General de Información y Documentación, 5(2), 153-162.

Ayuso, M. D. (2004). El Tratado de Documentación: el libro sobre el libro: teoría y práctica. La Habana: Félix Valera.

Brandi, C. (1988). Teoría de la Restauración. España: Alianza Forma. 
Braungart, M. \& McDonough, W. (2005). Cradle to cradle. Madrid: McGraw-Hill.

Chávez, J. Y Álvarez, O. (2005). Metodología para el Diagnóstico y restauración de las edificaciones. Revista de la Construcción, 2(4), 47-54.

Chanfón, C. (1988). Fundamentos teóricos de la restauración. México: UNAM.

Cruz M. J. R. (1994). Manual de archivística. Madrid: Fundación Germán Sánchez Ruipérez.

Dirección de Museos. (2020). Centro de Documentación Presidente Adolfo López Mateos. Toluca: Universidad Autónoma del Estado de México.

Dorta-Duque, M. E., \& Patallo E., B. (2009). 50 años en favor de la conservación patrimonial y el desarrollo cultural de América Latina y El Caribe: evidencias de la contribución de una biblioteca de ciencias sociales a este fin. En: IFLA, Libraries create futures: building on cultural heritage. 75th IFLA General Conference and Council llevada a cabo en el World Library and Information Congress. IFLA, Milán.

Druot, F., Lacanton, A., y Vassal, P. (2007), Plus. Barcelona: Gustavo Gili.

Encina M., M. (1994). Criterios de organización de un centro de documentación jurídica. Documentación de las Ciencias de la Información, s/v(17), 242-247.

Gutiérrez, A., Zárate, F., y Mirabal, O. (2010). Programa de necesidades de espacios del Centro de Información y Documentación de la Universidad Politécnica de San Luis Potosí: un proyecto logrado. Biblioteca Universitaria, 12(2), 202-2015.

Herrera-Miranda, I., Licea de Arenas, J., y Gómez-Hernández, J. A. (2013). Publicaciones Periódicas en Biblioteconomía, Bibliotecología, Ciencias de la Información y Documentación en México: Tendencias Temáticas, Productividad y Redes de Coautoría: 1956-2006. Revista Interamericana de Bibliotecología, 36(2), 97-108. https://doi.org/10.13140/RG.2.1.3297.5443

Latham, D. (2000). Creative re-use of buildings. V. 1. Shaftesbury: Dohead.

Lelis García, H. y Mireles Cárdenas, C. (2002). Aportaciones de Paul Otlet a la bibliotecología actual. Liber: Revista de bibliotecología, nueva época, 4(3). 22-26.

López de Quintana, E. (1995). Información multimedia en el entorno de la imagen: el centro de documentación de Antena 3 Televisión. Cuadernos de Documentación Multimedia, s/v(4), 1-13. Recuperado de http://dialnet.unirioja.es/servlet/ extart?codigo $=1024651$

López Yepes, J. (2015). La información en el origen y desarrollo de la Documentación. Italian Journal of Library and Information Science, 6(2), 127-141.

Martín M., F. (1987). Los Centros de Documentación publicitarios. Conceptos y Tipología, Madrid: Unión Editorial.

Martínez F., D. (2010). Los tesauros. España: UOC.

Martínez M., M. (2012). Reciclaje de arquitectura vs restauración arquitectónica, ¿herramientas contrapuestas? Hábitat y Sociedad, s/v(5), 23-33. https://doi. org/10.12795/HabitatySociedad.2012.i5.03

Millán, M. C. (2003). Las bibliotecas especializadas y los centros de documentación: situación en el Sistema Andaluz de Bibliotecas y Centros de Documentación. Boletín de La Asociación Andaluza de Bibliotecarios, 18(73), 9-39.

Mireles C., C., \& Arellano R., J. A. (2015). Normatividad sobre Arquitectura Bibliotecaria en México, elemento imprescindible para la oferta de servicios de información. Investigación Bibliotecológica, 29(66), 169-196. https://doi.org/10.1016/j. ibbai.2016.02.030

Montilla, L. J. (2013). El tratado de documentación de Paul Otlet: una exposición metacientífica. Biblios, s/v(51), 57-69, https://doi.org/10.5195/biblios.2013.93

Navarro, A. (2016). Estrategias de reciclaje arquitectónico. (Tesis de Doctorado). Universitat Politécnica de Valencia, Valencia, España.

Peiró G., M. de las N. (2001). El archivo como espacio del saber. El edificio de archivo. Boletín Millares Carlo, s/v(20), 245-279. 
Rojas, J. A. (2011). Procedimientos y tecnologías en la restauración: arquitectura, conjuntos y naturaleza. (Tesis de Maestría) Facultad de Arquitectura: UNAM, México. https://ru.dgb.unam.mx/handle/DGB_UNAM/TES01000670840

Ros, J. (1996). Los centros de documentación: planificación técnica general. En J. López-Yepes (Ed.), Manual de información y documentación (pp. 125-135). Madrid: Pirámide.

Rubio L., M. C. (2004). El análisis documental: indización y resumen en bases de datos especializadas. e-prints in library and information science, $s / v(s / n), 1-13$.

Rubio L., M. C., Maldonado Martínez, Á., \& Fages, C. (1992). La información y documentación en Ciencias Sociales y Humanas. Análisis comparativo de dos centros nacionales: El INIST-CDSH (Francia) y el CINDOC-Ciencias Humanas y Sociales (España). En: Nuevos mundos en información y documentación. $46^{\circ}$ Congreso FID, España.

Sargent, C., Parker, S., y Marcella, R. (2000). The provision of European information to the academic community in university libraries: a case study of a European Documentation Centre. New Library World, 101(4), 161-175. https://doi. org/10.1108/03074800010332829

Universidad Autónoma del Estado de México. (2020). Centro de Documentación Presidente Adolfo López Mateos. Toluca: Universidad Autónoma del Estado de México.

Velázquez, L.A. (2014). Museo de Historia Natural 16. Toluca: Universidad Autónoma del Estado de México. http://ri.uaemex.mx/handle/20.500.11799/4092

Leyes y documentos:

Ley Federal sobre Monumentos y Zonas Arqueológicos, Artísticos e Históricos. Diario Oficial de la Federación, Ciudad de México, México, 16 de febrero de 2018. 